\title{
Impact of Food Intake on Nutritional Status, Serum Calcium and Serum Iron of Children from 0 to 5 Years in Abidjan
}

\author{
Mohamed Ba Kone, Souleymane Traore, Kouakou Brou \\ Department of Food Sciences and Technology, Laboratory of Nutrition and Food Safety, Nangui Abrogoua University, Abidjan, Ivory Coast \\ Email address: \\ mohamedba84@live.fr (M. B. Kone) \\ To cite this article: \\ Mohamed Ba Kone, Souleymane Traore, Kouakou Brou. Impact of Food Intake on Nutritional Status, Serum Calcium and Serum Iron of \\ Children from 0 to 5 Years in Abidjan. International Journal of Nutrition and Food Sciences. Vol. 4, No. 4, 2015, pp. 439-444. \\ doi: $10.11648 /$ j.ijnfs.20150404.14
}

\begin{abstract}
The aim of this study is to contribute to improve the nutritional status of children under 5 years old in six districts of the city of Abidjan (Abobo, Koumassi, Yopougon, Treichville, Marcory and Cocody). This study was conducted on a cohort of 480 children at the rate of 80 children per municipalities. The results showed a negative correlation $(p<0.005)$ between the increase in macronutrient intake and prevalence of protein-energy malnutrition. The iron status of children is negatively affected by higher intakes of fiber, phytates and polyphenols $(\mathrm{p}<0.005)$. However, higher intakes of vitamin $\mathrm{C}$ and iron are associated with higher serum iron with respective positive correlation $\mathrm{R}^{2}=0.903$ for iron and $\mathrm{R}^{2}=0.563$ for vitamin $\mathrm{C}(\mathrm{p}<0.005)$. Contrary to the serum iron, serum calcium concentrations remain constant regardless of the contributions in anti-nutritional factors and nutrients to improve it, such as vitamin $\mathrm{C}$ and calcium.
\end{abstract}

Keywords: Children, Food Intake, Nutritional Status, Serum Calcium, Serum Iron

\section{Introduction}

In developing countries, protein-energy malnutrition and micronutrient deficiency are real public health problems [1]. Studies conducted by WHO in 2001 showed that children from 0 to 5 years are particularly vulnerable to these nutritional disorders because any deficiency at this age can lead to irreversible consequences. In addition, it was established that a child who does not get enough nutrients in his daily diet is exposed to various forms of malnutrition such as protein-energy malnutrition (PEM), nutritional anemia and xerophthalmia [2]. Calcium deficiency has also a significant impact on the child growth. It is unfortunately not uncommon that a child bears both and to varying degrees of the traces of these different forms of malnutrition [3]. In sub- Saharan Africa, the World Health Organization (WHO) in 2008 recorded more than 8 million children affected by protein-energy malnutrition (PEM) more or less severe, which can affect their physical and intellectual development and, ultimately, their ability to participate in the development of their country [4]. Recent work in Niger, Mali, and Burkina Faso showed that child with malnutrition remains a serious public health problem $[3,4,5]$. In these three countries, stunting affects approximately $45-61 \%$ of children under 5 years old, while the prevalence of underweight (weight / age) is 32 to $64 \%$. As for the children victims of micronutrient deficiency (mainly iodine, iron and vitamin A), it was estimated that there were 11 million children in 2009 in West Africa [6]. Ivory Coast, mainly agricultural country, unfortunately, is not ruled out by child malnutrition. The prevalence of PEM among children in northern Cote d'Ivoire is estimated at over $40 \%$ [7]. To the west of the country, the SMART report found a prevalence of $37 \%$ of the MPE in children [8]. In addition, at the clinical level, work has shown that over $70 \%$ of children under 5 suffer from anemia in Côte d'Ivoire $[9,10]$. Anemia can be due to various factors such as sickle cell anemia, intestinal parasites, but the major cause of this condition is iron deficiency. Data on calcium deficiency are almost nonexistent. However, stunting affecting 54\% of children in West Africa could be related to calcium deficiency. Dietary intake plays a major role in preventing all forms of malnutrition aforementioned. It therefore important to solve the problems of malnutrition in children, to properly understand their nutritional intake. It is in this context that we have undertaken this study which aims to assess the nutrient intakes of children under five and establish correlations with the three forms of protein-energy malnutrition, iron status and serum calcium. 


\section{Materials and Methods}

\subsection{Study Population}

This study is a descriptive cross-sectional survey that examined 480 children in 6 municipalities of the city of Abidjan, Ivory Coast. The municipalities involved areAbobo, Cocody, Koumassi, Marcory, Treichville and Yopougon with 80 children by municipalities.

\subsection{Assessment of Nutritional Status of Children}

The nutritional status of children has been assessed from the usual indices based on the combination of weight, size, age and sex:

- The index height-for-age that can identify children with growth failure

- The index weight for height that identifies the subjects children to emaciation.

- The index weight-for-age that can identify children who are underweight.

\subsection{4-hour Recall}

The 24-hour recall began with a parent has with the children so that they provide information about their food consumption the night before. Then, a short questionnaire is subjected children to fill possible omissions of the parents. Respondents were then asked subjects to estimate the quantities of food consumed. Finally, the intake of nutrients and anti-nutrients are obtained after biochemical assay of food.

\subsection{Determination of Serum Calcium}

Two $2 \mathrm{ml}$ blood taken beforehand are centrifuged at 3500 revolutions / second for 10 minutes. The plasma obtained after centrifugation is collected in Eppendorf tubes $(1.5 \mathrm{ml})$ and deproteinized with sulfosalicylic acid. After stirring, the tubes were centrifuged at 3500 revolutions / second for 10 minutes. The pellet containing the deproteinized plasma is mixed with an oxalate buffer with a ratio $2 / 3$. After standing for 30 minutes, the resulting mixture was centrifuged as before. The resulting precipitate was dissolved in perchloric acid and the whole is stirred vigorously for 10 seconds. To determine serum calcium, the flame photometer is set at the position of the calcium filter. The goal is to get the value zero for distilled water and 50 for the calcium chloride solution. After calibrating the photometer, the plasma concentration of ionized calcium in $\mathrm{mg} / 100 \mathrm{ml}$ is calculated by dividing the numerical value given by the flame photometer by 5 because of dilution.

\subsection{Determination of Serum Iron}

In a centrifuge tube of $20 \mathrm{ml}$, is placed $3 \mathrm{ml}$ of serum previously taken which are added $1.5 \mathrm{ml}$ of $\mathrm{ClHN}$ (Ammonium chloride) to ensure ionization of serum iron. After stirring followed by a rest period of 10 minutes, was added $3 \mathrm{ml}$ of $20 \%$ trichloroacetic acid. The whole is then centrifuged for 15 minutes at 4000 revolutions / minute. The clear supernatant was decanted in a small graduated cylinder. We note the volume (n) collected. This volume is transferred into a volumetric flask of $10 \mathrm{ml}$. Two drops of para-nitrophenol is added in alcoholic solution to $1 \%$ and then neutralized with ammonia until the color changes to yellow. We reacidified a few drops of $\mathrm{SO}_{4} \mathrm{H}_{2} \quad(0.5 \mathrm{~N})$ until discoloration. To the obtained colorless liquid, are added $1 \mathrm{ml}$ of aqueous $2 \%$ hydroquinone solution $\mathrm{B}$ and $0.5 \mathrm{ml}$ of aqueous O-phenanthroline solution at $0.5 \%$. The volume is then made up to $10 \mathrm{ml}$ with bidistilled water. The reagents are mixed by shaking and colorimetry is performed after a rest of one hour. After mixing, the color will develop for 1 hour, then the measurement is made at MILLER colorimeter.

\subsection{Statistical Analysis}

Significance levels of the effects of food intake on nutritional status, and hematological parameters of children were studied. Where a factor included more than two levels or modalities, the corresponding results are compared in pairs by the Chi-2 test to determine those among them present a significant difference.

\section{Results}

\subsection{Impact of Food Intake on the Nutritional Status of Children}

\subsubsection{Impact of Dietary Intake on Wasting}

Figure 1 shows the relationship between dietary intake and wasting. Correlations between macronutrient intake and wasting are very high. The results showed correlations: $\mathrm{R}^{2}=$ 0.862 for protein intakes, $\mathrm{R}^{2}=0.894$ for carbohydrate intake, and $\mathrm{R}^{2}=0.901$ for fat intake $\mathrm{p}<0.005$. The average prevalence of wasting is reduced by about $8 \%$ to $3 \%$ when the protein intake increased by 20 to $80 \mathrm{~g} / \mathrm{d}$; from $7 \%$ to $4 \%$ when the carbohydrate intake increased by 10 to $220 \mathrm{~g} / \mathrm{d}$ and from $8 \%$ to $4 \%$ when the lipid contributions increase by 15 to $40 \%$.

\subsubsection{Impact of Food Intake on Stunting}

Figure 2 shows the relationship between food intake and stunting. There is a strong negative correlation between protein intake and growth retardation $\left(\mathrm{R}^{2}=0.911\right) \mathrm{p}<0.005$. Thus, when the protein intake increases from 15 to $80 \mathrm{~g} / \mathrm{d}$ the average prevalence of children with stunted growth decreases from $40 \%$ to $7 \%$. The increase in carbohydrate and lipid intake is also associated with a lower prevalence of stunting but with lower correlations, however, $\mathrm{R}^{2}=0.514$ respectively for carbohydrate intake and $\mathrm{R}^{2}=0.511$ for fat intake $\mathrm{p}<0.005$.

\subsubsection{Impact of Food Intake on Underweight}

Figure 3 shows the relationship between food intake and weight insufficient. Overall, the increased intake of macronutrients (carbohydrates, protein and fat) is associated with a significant reduction of underweight in children $\mathrm{p}<0.005$. However, the highest correlation is the one between carbohydrates with underweight $\left(\mathrm{R}^{2}=0.899\right)$. Indeed, the average prevalence of underweight is $20 \%$ in children with a carbohydrate intake of about $110 \mathrm{~g} /$ day down to less than $5 \%$ 
in children receiving more than $200 \mathrm{~g}$ of carbohydrates per day.

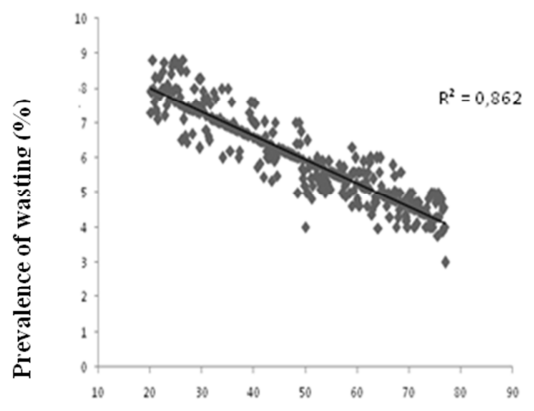

(a) Proteins intake $\mathrm{g} / \mathrm{d}$

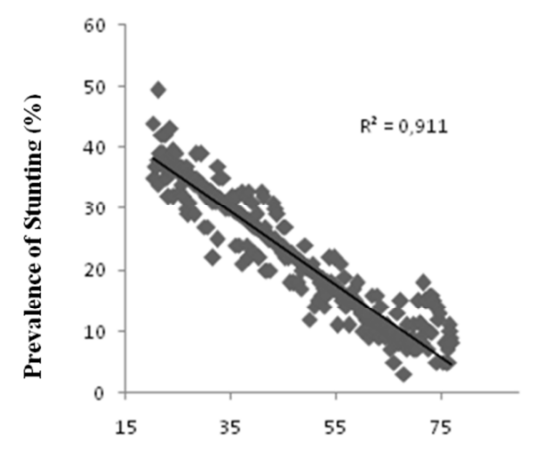

(a) Proteins intake g/d

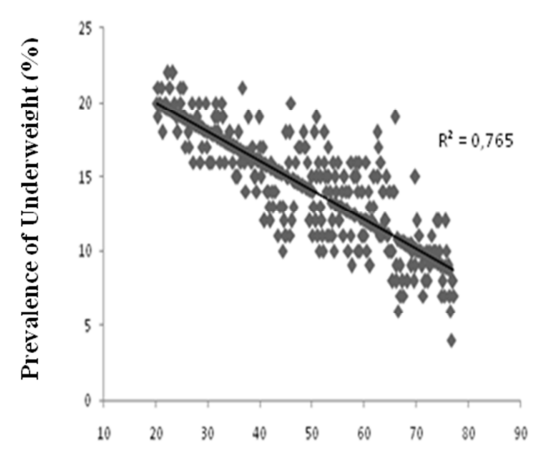

(a) Proteins intake $\mathrm{g} / \mathrm{d}$

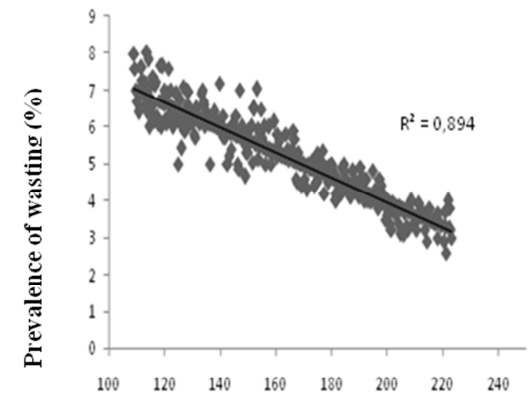

(b) Carbohydrates intake $\mathrm{g} / \mathrm{d}$

Figure 1. Impact of food intake on wasting.

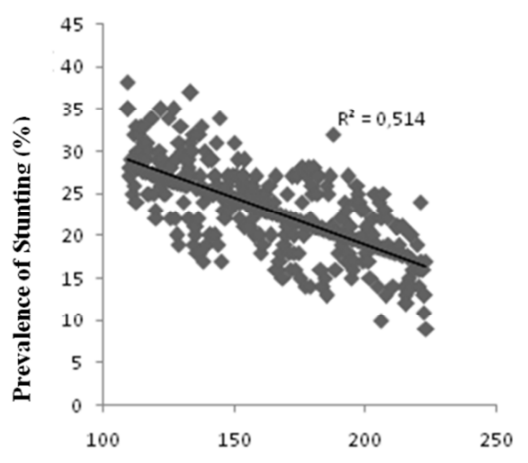

(b) Carbohydrates intake $\mathrm{g} / \mathrm{d}$

Figure 2. Impact of food intake on stunting.

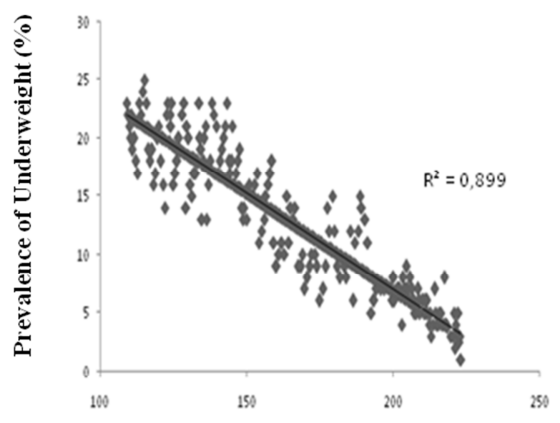

(b) Carbohydrates intake $\mathbf{g} / \mathbf{d}$

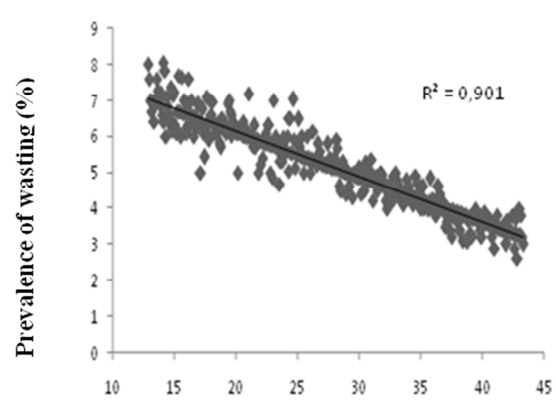

(c) Fats intake $\mathrm{g} / \mathrm{d}$

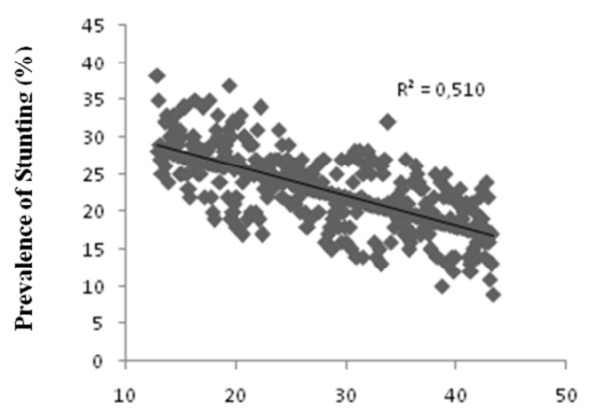

(c) Fats intake g/d

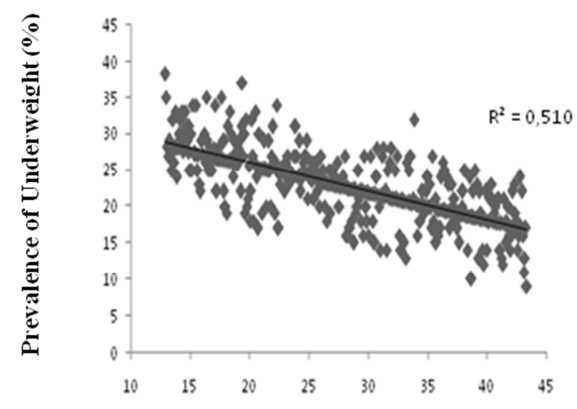

(c) Fats intake $\mathbf{g} / \mathbf{d}$

Figure 3. Impact of food intake on underweight.

\subsection{Impact of Food Intake on Serum Iron and Serum Calcium}

\subsubsection{On Serum Iron}

The iron status of children is negatively affected by higher intakes of fiber, phytates and polyphenols (Figure 4). Correlations between serum iron and various anti-nutritional factors are respectively $R^{2}=0.556$ for fibers, $R^{2}=0.493$ for the polyphenol, $\mathrm{R}^{2}=0.506$ for phytate $\mathrm{p}<0.005$.

However, higher intakes of vitamin $\mathrm{C}$ and iron are associated with higher serum iron with respective positive correlation $\mathrm{R}^{2}=0.903$ for iron and $\mathrm{R}^{2}=0.563$ for vitamin $\mathrm{C}$ $\mathrm{p}<0.005$.

\subsubsection{On Serum Calcium}

Figure 5 shows near-zero correlations between serum calcium and anti-nutritional intake, vitamin $\mathrm{C}$ and calcium. Contrary to the serum iron, serum calcium concentrations remain constant regardless of the contributions in anti-nutritional factors and nutrients to improve it, such as vitamin $\mathrm{C}$ and calcium. 
442 Mohamed Ba Kone et al: $\quad$ Impact of Food Intake on Nutritional Status, Serum Calcium and Serum Iron of Children from 0 to 5 Years in Abidjan
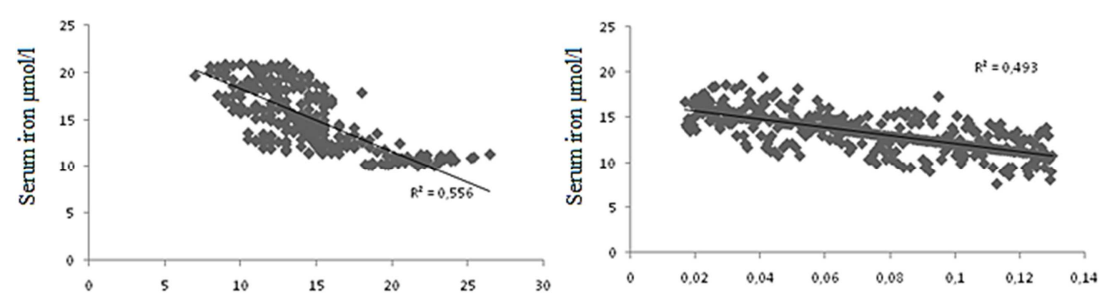

(a) Phytate intake $\mathrm{g} / \mathrm{d}$

(b)

Polyphenol intake g/d
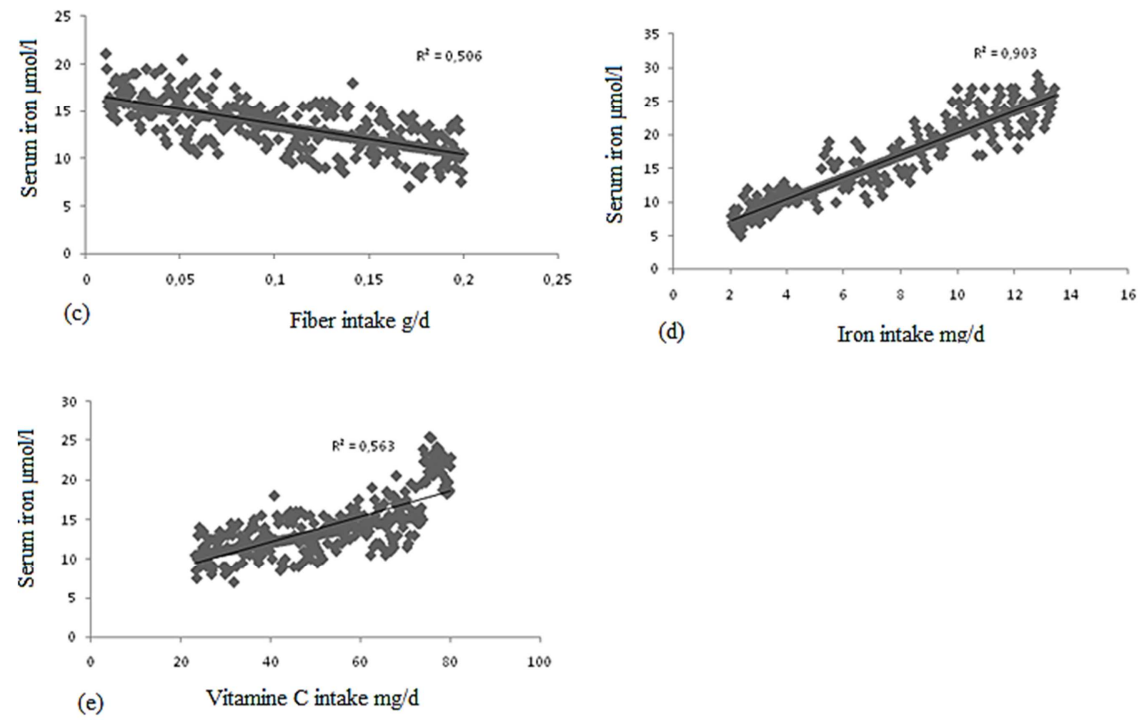

Figure 4. Impact of food intake on serum Iron.
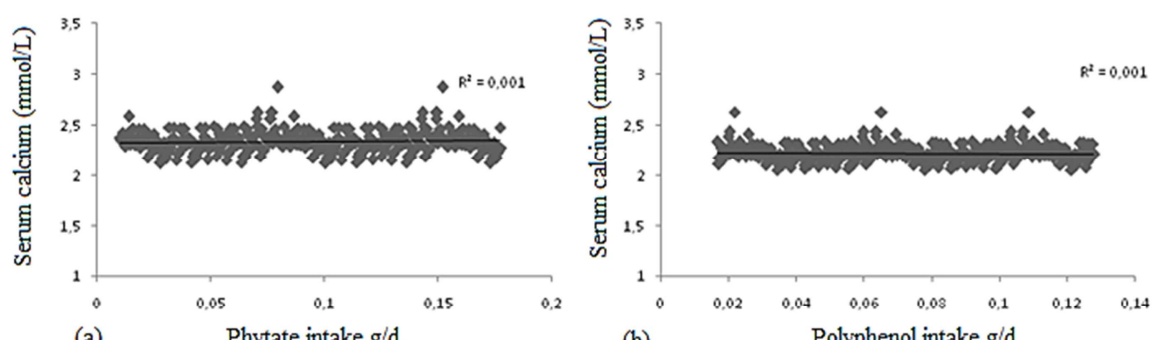

(a) Phytate intake $\mathrm{g} / \mathrm{d}$

(b)
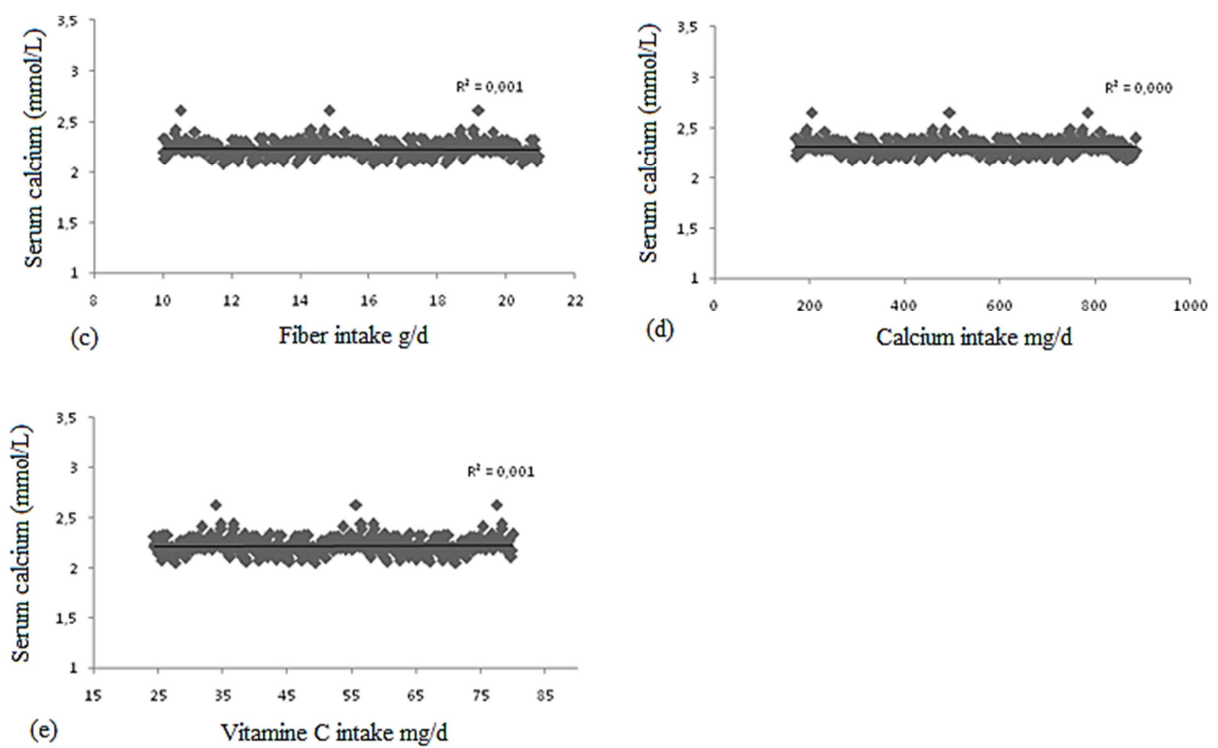

Figure 5. Impact of food intake on serum calcium. 


\section{Discussion}

Increased intakes of macronutrients (protein, carbohydrates and fat) leads to significant reductions of the three forms of protein-energy malnutrition (wasting, stunting and underweight) in children. These results are similar to observations of many authors who have shown that protein-energy malnutrition results from a deficiency of macronutrients [11,12,13].

Furthermore, it was demonstrated that in children, reduced protein intake is associated with a $67 \%$ increase in stunting [14]. It has been established that a protein deficiency causes a loss of bone mass (osteopenia) and loss of muscle mass (sarcopenia). In addition, a daily carbohydrate intake below 4 $\mathrm{g} / \mathrm{kg}$ in children are associated with wasting and underweight [15]. The carbohydrate deficit could cause the body to dip into fat reserves which leads to weight loss of the child. The results concerning the role of lipids in protein-energy malnutrition differ according to the authors. As some authors suggest that adequate intake of carbohydrates and protein are sufficient to prevent protein-energy malnutrition, independent of lipid intake [16]. By cons, others have shown that a daily intake of fat from $2 \mathrm{~g} / \mathrm{kg}$ in children allowed to reduce by $22 \%$ underweight [17].

At the level of serum iron, it was established that increased intakes of fiber, phytates and polyphenols is correlated with lower serum iron. These antinutrients (fibers, polyphenols and phytates) are responsible for the decreased absorption of nutrients in the intestinal lumens[18]. Increased intakes of vitamin $\mathrm{C}$ and iron are positively correlated with serum iron. It has been shown that serum iron increased by $83 \%$ for iron and $67 \%$ for vitamin $C[19]$. Consuming foods rich in iron and vitamin $\mathrm{C}$ may reduce the risk of iron deficiency and anemia in children. Indeed, in children 6 to 36 months, it has been demonstrated that the introduction of foods such as meat and giblets to decrease from 42 to $76 \%$ cases of anemia [17]. Some authors have also shown that eating citrus fruits such as orange, tangerine and lemon substantially improve the absorption of non-heme iron from plant foods [20].

Regarding serum calcium no correlation was observed with both micronutrient intake (vitamin $\mathrm{C}$, calcium) as anti-nutrients (fiber, phytates and polyphenols). Whatever the food consumed the calcium content remains stable in the body. Similar observations were reported by other authors. It has been demonstrated that in preschool-age children, notwithstanding the low intakes of calcium in serum calcium remained constant [21]. In addition, constant intake of calcium rise to any increase in calcium levels in the urine (urinary calcium), but not in blood [22]. The constant level of calcium in the blood regardless of food eaten may be due to a calcium-regulating mechanism in the body. This control system leads the body to dip into bone calcium reserves necessary to maintain stability in serum calcium. If the calcium content is high following the consumption of foods rich in calcium, the body will remove excess calcium in the urine. It was established that the body by drawing calcium in the bone reserves would entail a risk of demineralization of the bone structure, stunting and rickets, dry skin and broken nails in children [21]. It is therefore essential to provide the body the calcium necessary for its operation.

\section{Conclusion}

This study showed that nutritional and hematological status of children is closely linked to their diet. In fact, there is a negative correlation between the increase in macronutrient intake and the prevalence of protein-energy malnutrition. In addition, there is a negative correlation between the contributions of anti-nutrients and serum iron while high intakes of vitamin $\mathrm{C}$ and iron have a positive impact on serum iron content. Whatever micronutrient intake and antinutritiments serum calcium does not vary among all children surveyed.

\section{References}

[1] Dewey KG., Crooks H., Adu-Afarwuah S. (2004). Systematic review of the efficacy and effectiveness of complementary feeding interventions in developing countries. Matern Child Nutr 4: 24-85

[2] Mendez B., Adair J. (2001). Socioeconomic and demographic factors are associated with worldwide patterns of stunting and wasting. J Nutr. 127: 2302-2309

[3] Amara RE. (2009). La malnutrition infanto-juvenile : aspects épidémiologiques et prise en charge dans le district sanitaire de Koutiala (Mali). Mémoire faculté de medecine Mali 54p

[4] Ilboudo N. (2004). Les déterminants de la malnutrition des enfants au Burkina faso. Memoire de Master, Institut de recherche empirique en économie politique, $79 \mathrm{p}$.

[5] Damiba EA. (2002). Enfance, Nutrition et Sécurité alimentaire au Niger. Ford Chall 3: 55-70.

[6] Organisation mondiale de la santé. (2009). données statistiques, World Health Pub, $25 \mathrm{p}$

[7] Aké-Tanoh O., Tiembré I., Konan J. (2009). Severe acute malnutrition among children under five years of age in Côte d'Ivoire. Asian Pediatrics 5: 47-51

[8] SMART. (2006). Ivory Coast national health survey related to children. $26 \mathrm{p}$.

[9] Asobayire FS., Adou P., Davidsson L., Cook JD., Hurrell RF. (2001). Prevalence of iron deficiency with and without concurrent anemia in population groups with high prevalences of malaria and other infections: a study in Côte d'Ivoire. $\mathrm{Am} \mathrm{J}$ Clin Nutr 74:776-82.

[10] Rohner F., Zimmermann MB., Amon R.J., (2010). In a randomized controlled trial of iron fortification, anthelmintic treatment, and intermittent preventive treatment of malaria for anemia control of Ivorian children, only anthelmintic treatment shows modest benefit. J Nutr 140: 635-641. 
444 Mohamed Ba Kone et al: $\quad$ Impact of Food Intake on Nutritional Status, Serum Calcium and Serum Iron of Children from 0 to 5 Years in Abidjan

[11] Kidney L, Randy C, (1991). The role of dietary calcium and other nutrients in moderating body fat in preschool children. Int J Metab Disord 25: 559-566.

[12] Hackman Z., Cousens S., Akhund T., Khan J. (2001). Effect of provision of daily zinc and iron with several micronutrients on growth and morbidity among young children in Pakistan. Lancet 32: 29-40.

[13] Clooney G. (2005). Nutritional influences on linear growth: a general review. Eur J Clin Nutr 48: 75-89.

[14] Bogats V., Sylla A., Diouf S., Sall MG., Ndiaye O., Moreira C., Kuakuvi N. (2009). Predictive factors of death in a pediatric service from Dakar: diarrhea and brachial perimeter. Arch Pediatr 9: 557- 58.

[15] Heaney G. and Layman F. (2006) Food intake and PEM trought children under five. Clin Nutr 74:776-82.

[16] Felbs M., Michaelsen K., Larnkjær A. (2009). Amount and quality of dietary proteins during the first two years. Nutr Metab Dis 22: 781-6.

[17] Newman F., Bhattacharya J Currie J., Haider S., (2009). Poverty, food insecurity, and nutritional outcomes in children and adults. $J$ Health Econ 23:839-862.
[18] Layrisse M., Victoria, C., Barros, F., Vaughan JP (2000). Diarrhea, and growth in the first 4 y of life: a longitunal study of 5914 urban Brazilian children. Am J Clin Nutr 52:391-396

[19] Cook F., Reddy D. (2001). Complex interactions with infection and diet may explain seasonal growth responses to vitamin A in preschool aged Indonesian children. Eur J Clin Nutr 58: 90-99.

[20] Lambertini, F., Madise, N., Whitworth, A., Matthews, Z. (2007). A multilevel comparison of the determinants of child nutritional status from selected African and Indian regions. Health Place 10: 183-199

[21] Garabedian M., Carruth B., Skinner J. (2005). The role of dietary calcium and other nutrients in moderating body fat in preschool children. Int J Metab Disord 25: 559-566.

[22] Validation Issues in Questionnaires for Diagnosis and Monitoring of Gastroesophageal reflux Disease in Children. Current malnutrition report 12: 230-236.

[23] Boeker F., Kleinman L., Revicki DA., Flood E. (2013). Validation Issues in Questionnaires for Diagnosis and Monitoring of Gastroesophageal reflux Disease in Children. Current malnutrition report 12: 230-236. 